\title{
G
}

COUNTERFUTURES

Left thought \& practice Aotearoa

FIVE

2018 


\section{Zines and Politics}

\section{Bryce Galloway}
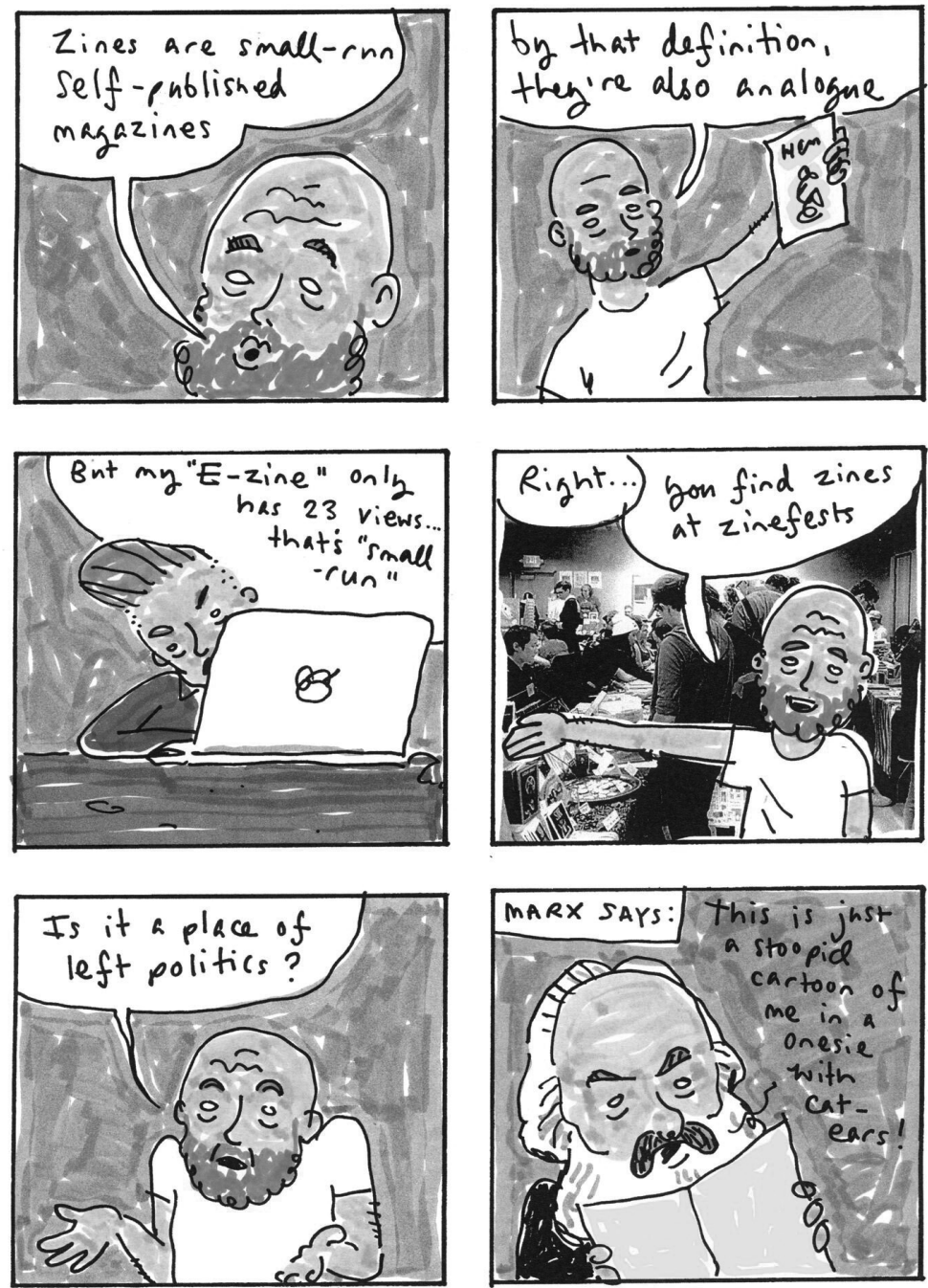

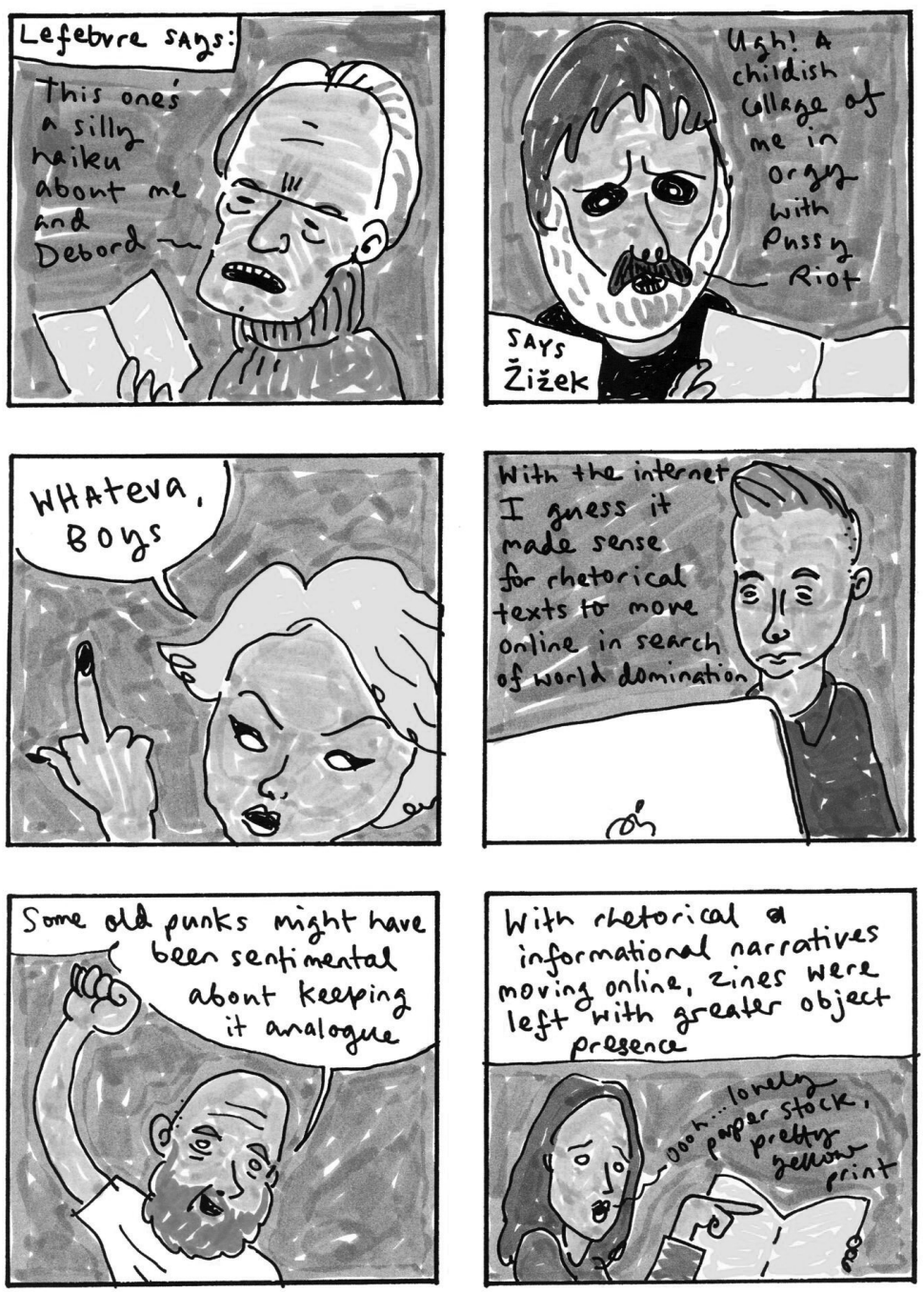

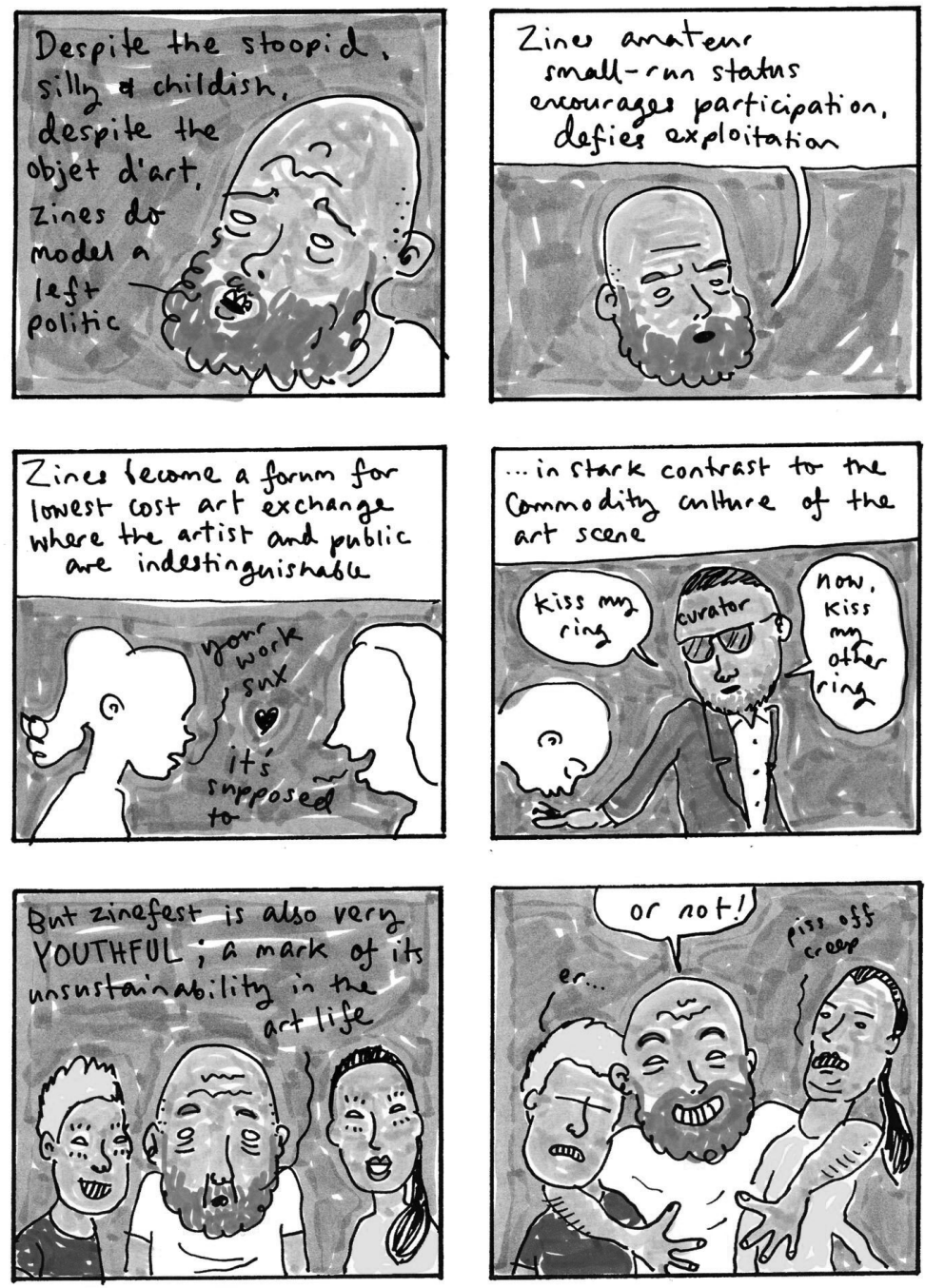
If you like what you have read, please subscribe or donate.

\author{
G \\ COUNTERF UTURES \\ Left thought \& practice Aotearoa \\ (C) Copyright Counterfutures 2018
}

